\title{
Riuen les meduses: cos i desig a la poesia de Carmelina Sánchez- Cutillas i Maria-Mercè Marçal
}

\section{Medusa's laughter: body and desire in the poetry of Carmelina Sánchez-Cutillas and Maria-Mercè Marçal}

NoÈlia Díaz Vicedo

n.diaz-vicedo@qmul.ac.uk

Queen Mary University of London

\begin{abstract}
Resum: Aquest article estudia per primera vegada les continuïtats entre la poesia de Maria-Mercè Marçal (1952-1998) i Carmelina Sánchez-Cutillas (1921-2009). Específicament, se centra en l'obra poètica publicada en vida de les dues escriptores i que es troba recollida dins Llengua abolida (1973-1988) (1989) de Marçal i Obra poètica (1997) de Sánchez-Cutillas. Encara que les condicions sociohistòriques són diferents entre les dues poetes, en aquest article intentaré demostrar que l'escriptura en totes dues beu directament de la seua experiència vital donada per la posició del seu cos de dona i la interacció intel lectual amb el llenguatge i els significats culturals heretats. Des d'aquests qüestionaments, en aquest article oferiré una aproximació al contínuum de la problemàtica de la subjectivitat femenina, nucli de la seua obra, des de la interacció entre cos i llenguatge, paràmetres centrals que ocupen els estudis de la diferència sexual, en particular en la teoria denominada écriture féminine desenvolupada per les filòsofes Hélène Cixous i Luce Irigaray.
\end{abstract}

Paraules clau: cos, desig, Carmelina Sánchez-Cutillas, Maria-Mercè Marçal, écriture féminine

\begin{abstract}
This article explores for the first time the continuities between the poetry of MariaMercè Marçal (1952-1998) and Carmelina Sánchez-Cutillas (1921-2009). Particularly, it focuses upon the poetic works published during their lifetime, collected in the volumes Abolished Language (1973-1988) (1989) by Marçal and Poetic Works (1997) by Sánchez-Cutillas. Despite their different socio-historical conditions, in this article I analyse how their vital particular experiences as female subjects become the cornerstone of their writing and how the position of their body interacts with language, consequently challenging their inherited socio-cultural significations. In order to discuss my points, I draw upon the parameters developed by the theoretical framework of écriture féminine developed by philosophers Hélène Cixous and Luce Irigaray.
\end{abstract}

Keywords: body, desire, Carmelina Sánchez-Cutillas, Maria-Mercè Marçal, écriture féminine

DATA PRESENTACIÓ: 01/05/2021 ACCEPTACIÓ: 14/05/2021 •PUBLICACIÓ: 01/06/2021 
Noèlia Díaz Vicedo. Riuen les meduses: cos i desig a la poesia de Carmelina Sánchez-Cutillas i

Maria-Mercè Marçal

Ploraré la teua absència al regne transparent de la medusa.

Carmelina Sánchez-Cutillas

Des de l'escut et fita

i t'emmiralla en pedra

-esdevinguda monstre-

la nuesa negada.

Maria-Mercè Marçal

\section{Introducció}

Aquest article estudia per primera vegada les continuïtats entre la poesia de Maria-Mercè Marçal (1952-1998) i Carmelina Sánchez-Cutillas (1921-2009). Específicament, se centra en l'obra poètica publicada en vida de les dues escriptores i que es troba recollida dins d'un sol volum, Llengua abolida (1973-1988) (1989) de Maria-Mercè Marçal i Obra poètica (1997) de Carmelina Sánchez-Cutillas editat pel poeta alacantí Lluís Alpera. Encara que totes dues van conrear altres gèneres literaris com la novel.la, la traducció d'altres dones escriptores i l'elaboració de teoria feminista en el cas de Marçal, o la investigació històrica i periodística per part de Sánchez-Cutillas, la producció poètica ocupa un lloc central en el conjunt de la seua obra. Totes dues van gaudir de cert reconeixement durant la seua vida, especialment arran de les úniques novel les que van escriure i que van ser premiades: amb Matèria de Bretanya Carmelina Sánchez-Cutillas va guanyar el premi OctubreAndròmina de narrativa l'any 1975 i Maria-Mercè Marçal amb La passió segons Renée Vivien (1994) va guanyar nombrosos premis entre ells el prestigiós Carlemany. ${ }^{1}$

Carmelina des del País Valencià i Maria-Mercè des de Catalunya són dos figures cabdals en la història de la literatura catalana del segle XX. Tot i la importància de la seua obra, la crítica ha estat prou distant i no han rebut l'atenció que mereixen. Només en els últims anys l'obra de Maria-Mercè Marçal ha estat considerablement estudiada i des de vàries perspectives com ara les teories de gènere i sexualitat i el feminisme, ${ }^{2}$ guanyant també una perspectiva internacional amb les traduccions a l'anglés de l'obra pòstuma Raó del cos [The Body's Reason] (2014), la publicació del primer monogràfic sobre la seua poesia i escrit en anglés que vaig titular Constructing the feminine Poetics in the Works of a Late 20th Century Catalan Woman Poet (2014) i el primer llibre d'assajos literaris sobre la seua obra Maria-Mercè Marçal: Her Life in Words (2017).

Pel que fa a l'obra de Carmelina, la situació és encara precària i els treballs d'investigació són encara escadussers, limitant-se fins el moment a alguns monogràfics de revistes editats a la seua

1 També va guanyar el «Premi de la crítica” (1995), «Premi Joan Crexells» (1995), «Premi Crítica Serra d’Or» (1995), «Premi Prudenci Bertrana» (1995) i el «Premi de la Institució de les Lletres Catalanes» (1996).

2 Destaquen els treballs de Riba (2014, 2015) i Tanna (2019).

SCRIPTA, Revista internacional de literatura i cultura medieval i moderna, núm. 17 / juny 2021 / pp. 520 - 537 ISSN: 2340-4841 · doi:10.7203/SCRIPTA.17.20922 
Noèlia Díaz Vicedo. Riuen les meduses: cos i desig a la poesia de Carmelina Sánchez-Cutillas i Maria-Mercè Marçal

obra com per exemple L'Aiguadolç (2017), Saó (2020), articles acadèmics i obres compartides amb altres autores com l'estudi Les dones fortes. La narrativa valenciana sota el franquisme (2019) de Maria Lacueva on Carmelina comparteix espai amb Maria Beneyto i Beatriu Civera. Lacueva se centra fonamentalment en l'exploració de la prosa produïda per aquestes dones escriptores en un context d'opressió cultural i de gènere derivat del marc polític de la dictadura franquista. Pel que fa a la poesia, en el cas de Carmelina, encara no hi ha un corpus d'estudi substancialment important sobre la seua obra. També va ser traduida a l'anglés en el volum $A$ Rebel World per la universitat de Kentucky als EUA l'any 1969. Carmelina ha estat estudiada des del punt de vista dels estudis biogràfics i memorística amb treballs de crítics com Joan Borja (2001) o Anna Esteve (2020), i des del punt de vista del realisme social Alpera (1997), Balaguer (2020) o Mira (2017). La investigació de la seua producció poètica des del punt de vista de gènere és un terreny encara per trepitjar a excepció de l'article d'Anna Cacciola (2019).

Encara que les condicions sociohistòriques són diferents entre les dues poetes, en aquest article intentaré demostrar que l'escriptura en Sánchez-Cutillas i Marçal beu directament de la seua experiència vital donada per la posició del seu cos de dona i la interacció intel lectual amb el llenguatge i els significats culturals heretats que les encerclen dins un model específic i determinat per l'aparat ideològic de la dictadura franquista basats en el control absolut del cos de la dona que havia d'acomplir el seu destí: la maternitat. Aquest model emmarca quasi la totalitat de l'existència de Sánchez-Cutillas i condiciona de forma directa la de Marçal. No només això, les dues poetes encara van més enllà de la particularitat sociohistòrica d'on emergeixen, i arriben també a qüestionar-la des dels fonaments de la cultura occidental a través de l'ús de la mitologia. Així Maria-Mercè es pregunta: «Què és ser dona? És ser com la mare o no? Com es compaginen unes tries "no femenines" amb el fet de continuar essent dona?» (Nadal 1989: 26) i Carmelina al poema «Fidelitat» del seu segon recull Conjugació en primera persona diu: «N'estàs contenta?, em pregunte/ cada dia en llevar-me del llit./ Estàs contenta d'ésser dona?» (1969: 121). ${ }^{3}$ Des d'aquests qüestionaments plantejats per les pròpies autores, el meu objectiu en aquest article és oferir una aproximació al contínuum de la problemàtica de la subjectivitat femenina, nucli de la seua obra, des de la interacció entre cos i llenguatge, paràmetres centrals que ocupen els estudis de la diferència sexual, en particular en la teoria denominada écriture féminine desenvolupada per les filòsofes Hélène Cixous i Luce Irigaray.

\section{2. «Tot perquè he sentit la crida, he intuït que hi ha altres normes $\mathrm{i}$ altres lleis»: cos $\mathbf{i}$ llenguatge}

Entendre el cos femení com a paràmetre principal de coneixement i font de creativitat és el plantejament teòric que desenvolupa Hélène Cixous al seu pioner assaig 'Le Rire de la Méduse'

3 Les referències a la poesia de Carmelina Sánchez-Cutillas seran totes referides de l'Obra poètica editada per Lluís Alpera l'any 1997.

SCRIPTA, Revista internacional de literatura i cultura medieval i moderna, núm. 17 / juny 2021 / pp. 520 - 537 ISSN: 2340-4841 · doi:10.7203/SCRIPTA.17.20922 
Noèlia Díaz Vicedo. Riuen les meduses: cos i desig a la poesia de Carmelina Sánchez-Cutillas i

Maria-Mercè Marçal

publicat l'any 1975 i traduït a l'anglés l'any 1976 per Keith i Paula Cohen, on utilitza per primera vegada el terme écriture féminine. En aquest assaig fa referència a com l'estructura de la llengua occidental és de fet l'instrument fonamental que ha perpetuat l'absència de la dona del sistema de pensament, i conseqüentment literari, configurant la subjectivitat femenina dins una identitat homogènia, única i excloent fonamentada en la repressió i el silenci del cos. La base d'aquest concepte de dona es basa en l'essència del cos com a una dimensió estàtica, uniforme, comuna $\mathrm{i}$ únicament predeterminada a la funció biològica maternal. Així, la dona entesa i configurada com a ésser natural ha estat exclosa de la possibilitat de la cultura. L'écriture fémenine proposa des dels paràmetres de la diferència sexual una disrupció d'aquests discursos mitjançant la incorporació del cos a l'espai literari com a font de coneixement i significants. Així. l'escriptura esdevé l'acte de l'elaboració de les experiències femenines viscudes, representades i escrites des d'un cos que no només té la capacitat de (re)producció, sinó també de producció. Tant Sánchez-Cutillas com Marçal eren ben conscients d'aquest aspecte, de la necessitat d'escriure les seues experiències, de la posició de la dona dins el context de la literatura i la seua història i dels reptes i entrebancs que comportava per a elles escriure des del cos i del dubte, la incertesa respecte a la tradició literària, tal i com el patriarcat l'havia baratada. Així, Carmelina ens parla de la dona que dormia, bategant i latent en una societat que l'havia silenciada. A les jornades sobre «Dona i literatura» celebrades a Benicarló en 1985, Carmelina reflexiona sobre la posició de la dona dins de la literatura i va dir:

\begin{abstract}
Jo, que deteste la paraula poetessa, no puc negar que la dona posa un sentiment particular en allò que escriu, com en tot el que fa; posa la seua forma especial de veure les coses, i les seues femenines experiències. Tanmateix, no crec que devem diferenciar una literatura femenina de la masculina. Clar que cal admetre que sempre contarà millor els problemes i les vivències d'una dona una altra dona. I l'interès per aquests problemes i per la condició femenina, és cada dia major en tot el món. Al cap i a la fi, som un ésser que ha dormitat al llarg dels segles, i que ara comencem a despertar-nos (Del Romero 2020: 49).
\end{abstract}

Amaneix en Sánchez-Cutillas i Marçal la necessitat d'una nova forma de dir i d'ésser. Desperta Sánchez-Cutillas i així es llança a escriure obeint la crida. Aquella veu, la remor que escolta el poeta i que li ve donada per la veu de la Musa, una altra dona invisible, que no té cos. Així el jo poètic encara sense saber com, ha obeï al desig de l'escriptura, però ho ha fet perquè ha escoltat, i agafa el llenguatge que se li ha negat a la seua subjectivitat i obri nous camins que «intueix» $\mathrm{i}$ es llança a la recerca d'altres lleis i normes com ens diu als últims versos del poema «Res no em commou» (p. 48):

Tot, perquè he sentit la crida, he intuit que hi ha altres normes $i$ altres lleis.

Però, romandre atansat, embussat als vells paranys. 
Noèlia Díaz Vicedo. Riuen les meduses: cos i desig a la poesia de Carmelina Sánchez-Cutillas i

Maria-Mercè Marçal

El moment preliminar al dia, el despertar historicosocial que experimenta Sánchez-Cutillas i sobre el qual reflexiona, serà el preàmbul necessari per a que poetes com Maria-Mercè Marçal des de la generació següent d'escriptores, encara que nascudes dins el règim dictatorial, ja veuen i viuen l'ésser dona dins d'un marc democràtic i de suposada llibertat on una consciència absoluta de la posició del seu cos és palesa. Marçal ben conscient d'aquesta diferència sexual també es va referir a aquesta problemàtica:

\footnotetext{
No debades tenim un cos diferent. Ens movem en una cultura que ha minimitzat molt el cos; el cos és la natura, l'important-sembla- és la raó i la raó no té sexe! Penso que hi ha, de segur, una vivència concreta de les dones, una vivència específica diferent (Montero 2004: 268).
}

\section{3. «El clam es fa inici i pren vida: pren vida en nosaltres»: vida $\mathrm{i}$ escriptura}

Maria-Mercè Marçal i Carmelina Sánchez-Cutillas venen al món en ciutats diferents on posteriorment viuran i situaran les seues arrels i referents culturals. Marçal naix circumstancialment a Barcelona l'any 1952 i Sánchez-Cutillas a Madrid el 1921. Vint-i-cinc anys separen els seus naixements i la distància generacional de la seua vida fan que tot i la centralitat del cos com a font de producció poètica, totes dues troben posicions oposades pel que fa a la funció de la poesia, el propòsit de l'acte de l'escriptura i la consciència de la condició de dones. Maria-Mercè estableix les seues bases literàries en un feminisme clar $i$ vindicatiu des del principi caracteritzat pel trencament polític i social dels anys de la dictadura franquista, mentre que Carmelina inserida dins d'aquest context declara la seua posició literària i social lluny d'aquesta perspectiva feminista que ella entén com una lluita de poders. Curiosament, no només reconeix públicament la situació de la dona en el context dictatorial que li ha tocat viure sinó que també hi participa. A l'acte del I Encontre internacional de la dona de la Mediterrània a València l'any 1992 diu:

\footnotetext{
Primer que tot faig la meua confessió: jo no sóc feminista. Feminisme és una paraula amb un significat molt ideològic: el de la lluita d'una classe per establir el seu domini enfront de l'altra. I el domini sempre implica sotmetiment. Ara bé, si que em declare enemiga acèrrima d'aquesta manifestació de dret de possessió i de poder, de l'home, del mascle, sobre la dona (Del Romero 2020: 49).
}

Marçal pel contrari entén el feminisme com una acció políticament necessària que lliga l'espai individual i col lectiu simultàniament, així la posició política es relaciona amb la literària com un binomi totalment vinculat i oscil lant que afecta totes dues esferes. Partint dels primers anys vindicatius i de caire polític del feminisme, Marçal gradualment va anar evolucionant cap a una concepció del feminisme més literari i conceptual on la poesia es converteix en l'espai de reescriptura de noves formes i significats de ser dona. En aquest sentit per a Marçal el feminisme: 
Lliga molt l'espai privat i el col lectiu. N'és indestriable, perquè com deia abans el problema principal és el tema de la identitat de les dones, i això és absolutament una barreja d'afirmació individual, d'aprofundiment en la teva experiència i de vinculació col lectiva (Montero 2004: 263).

Així i tot, quins paràmetres comparteixen aquestes dues poetes malgrat la distància espaciotemporal de les seues vides $i$ les seues obres? I encara més adient és el preguntar-nos com és establir un diàleg poètic entre les seues obres sense caure al parany dialèctic d'uniformitzar i essencialitzar la subjectivitat femenina que tan tràgiques conseqüències ha portat al llarg de la història? La raó del diàleg en aquest sentit correspon a un acte: el de l'escriptura i a un espai, el del cos de dona. La paraula, medi de transmissió on conflueixen tots dos acció i espai, és en aquest cas la paraula escrita. I la paraula escrita sempre porta en ella mateixa una càrrega històrica i cultural que l'escriptor sotmet a un procés de descodificació i reelaboració. Aquest procés en Sánchez-Cutillas i Marçal, com a escriptores dones, es troba de forma molt específica des del moment que prenen la decisió d'escriure i intervenen en la història de la literatura i en contra d'aquesta herència sociosimbòlica: el patriarcat. Si la paraula a l'home li ve donada en forma d'enigma, incertesa i misteri, ja ho va dir Sòcrates al Cràtil, a la dona la paraula, que li ha estat sempre negada i a qui no s'espera trepitjar, li ve donada de mans de l'home $\mathrm{i}$ ha estat ella, qui per voluntat pròpia i ferm propòsit d'intervenció històrica i literària que se l'ha apropiat. En aquest sentit, els punts específics i vitals que conformen el modus operandi de les dues poetes connecta directament amb el substrat del marc teòric de la diferència sexual, en particular de l'écriture féminine:

\footnotetext{
It is by writing, from and toward women, and by taking up the challenge of speech which has been governed by the phallus, that women will confirm women in a place other than silence. Women should break out of the snare of silence. They shouldn't be conned into accepting a domain which is the margin or the harem (Cixous 1976: 881).
}

Així i tot, tant Sánchez-Cutillas com Marçal conceben l'escriptura no solament com a part fonamental de la seua vida, sinó que la seua vida es converteix en literatura oscil lant entre els dos espais que alimenten l'un a l'altre. La sincronia de l'experiència vital del subjecte femení transcendeix a una diacronia històrica en el moment en el que aquesta experiència s'articula poèticament a través del llenguatge. Així vida i escriptura lliguen l'espai de la literatura. I així la literatura, com ens ha dit Cixous (1976), es converteix en l'espai on el trencament del silenci històric de la subjectivitat femenina té lloc. Maria-Mercè Marçal també va reflexionar sobre aquest aspecte:

escrius sobre la teua experiència vital, que, alhora, condiciona l'experiència posterior. Et vas donant un relat sobre tu mateixa a través dels poemes tot i que després puguis replantejarlo d'alguna manera ja està marcant la teva trajectòria. En aquest sentit, doncs, trobem una interacció. Primer seria la vida, però la literatura després torna a influir en la manera com es viuen els esdeveniments (Nadal 1989: 26). 
Noèlia Díaz Vicedo. Riuen les meduses: cos i desig a la poesia de Carmelina Sánchez-Cutillas i

Maria-Mercè Marçal

Carmelina Sánchez-Cutillas dirà:

La literatura ha estat i és el vehicle, el camí, el procediment per a dir el que volia. He contat els records del temps, de les coses; eixos records que em pugen a la gola com un glop de vi torbador. He llançat crits de protesta i rebel lió -com a Món rebeli a Conjugació en primera persona (Ventura Melià 1979: 39).

L'acció, doncs, es produeix amb els objectius ben clars que marquen una ruptura amb el passat i una reconfiguració del present, i plantegen que escriure esdevé, segons Cixous el crit de protesta i rebel lió o com a replantejament, com la voluntat de «to break up, to destroy; and to foresee the unforeseeable, to project» (1976: 875). Tot i que aquesta forma de rebel lió es manifesta de forma molt conscient en Maria-Mercè Marçal que adopta una posició feminista i vindicativa des del primer vers «a l'atzar agraeixo tres dons: haver nascut dona, de classe baixa i nació oprimida. I el tèrbol atzur de ser tres voltes rebel» (1989: 23) i d'una manera més transversal en Carmelina Sánchez-Cutillas, des de la foscor i el dubte que implica tot procés iniciàtic com ens diu al seu primer poema: «eixiré als camins a oferir-me galant [...] parlaré altre llenguatge, fet d'accents més sincers [...] tot, per trobar-hi la llum, en uns dubtes, en uns mots/ que arrossegue amb por des de l'adolescència» (41).

\section{4. «Ens feren el regal de dar-nos un nom»: la poesia i la realitat}

Com veiem, la rebel lia contra els discursos establerts, la necessitat d'altre llenguatge i la voluntat d'obrir nous espais, en totes dues autores confronten en els seus poemes el seu «ésser dona» com a punt de partida de la seua creativitat, donant a la poesia i l'escriptura l'espai de llibertat i reformulació del llenguatge que adapten a les seues pròpies necessitats d'autocreació. Aquest punt de partida és precisament el que ens proposa Cixous (1976: 875):

\footnotetext{
Woman must write her self: must write about women and bring women to writing, from which they have been driven away as violently as from their bodies - for the same reasons, by the same law, with the same fatal goal. Woman must put herself into the text - as into the world and into history — by her own movement.
}

Quines són les causes de la rebel lia de Sánchez-Cutillas i la necessitat de reescriptura de Marçal? Podem parlar d'un substrat comú que determine els dos punts de partida? De quina manera interaccionen amb la realitat de l'aquí $\mathrm{i}$ ara de l'escriptura que les envolta? Darrere de la necessitat $\mathrm{i}$ la rebel lia de la que parlen les nostres escriptores hi ha el desig, el desig d'escriure. I amb el desig sempre hi ha la raó, el per què s'escriu. I tant Carmelina com Maria-Mercè comparteixen una mateixa raó poètica que relaciona al seu jo poètic i individual amb la realitat. Sánchez-Cutillas diu: «escriure m’ajuda a fugir de la realitat» (Ventura Melià 1979: 38). Marçal es refereix a l'escriptura 
Noèlia Díaz Vicedo. Riuen les meduses: cos i desig a la poesia de Carmelina Sánchez-Cutillas i Maria-Mercè Marçal

com «el pany de realitat que cada autora, i cada autor, focalitza, selecciona per ser dit i salvat de l'oblit, o fins allò què és capaç d'imaginar (...) té molt a veure el lloc des del qual es parla, amb els sistema de valors compartit o discutit» (1996b: 159-60). Fugina, oblit, salvació, imaginació i sistema de valors són les característiques fonamentals que determinen el binomi realitat-poesia segons les nostres autores. A l'obra de Sánchez-Cutillas la determinació del realisme, pel que fa la primera poesia, ha estat fonamental segons la crítica. Així els poemaris Un món rebel i Conjugació en primera persona publicats al 1964 i 1969 respectivament, de forma quasi unànime, han estat considerats dins del moviment literari conegut com «realisme social» en paraules de Lluís Alpera (1997: 16) imperant en el conjunt de la literatura catalana del moment.

La realitat però que viu Carmelina i que es convertirà en el punt central d'aquests dos poemaris situa el jo poètic entre un «nosaltres-aquells» que han perdut una guerra, que han quedat silenciats. I les grans perdedores de la guerra, els «nosaltres silenciats» són les dones. Advocades a un silenci, no solament polític sinó de gènere, desposseïdes de qualsevol dret civil o legislatiu, tornades a la casa i tancades, després de la guerra les dones deixen de ser subjectes davant la llei i passen a ser adjacents i funcionals a la figura de l'home. Hi ha un «ells» i un «nosaltres» als poemaris que l'autora encara escriu en masculí, en un masculí neutre i universal que assimila la seua condició femenina, com el món que s'havia creat, que ells, els homes que havien guanyat la guerra i exercien un poder abusiu i totalitari havien creat i que «els calia/ tancar, occir els nostres crits/ amb un trist boç de ferro» (51). Però així $i$ tot hi ha el llamp de la poesia, el crit, la veu interna i primigènia que viu a l'ànima de Carmelina com a lletraferida i així ens ho diu al poema: «però seguíem udolant/ a la nit i a la lluna/ dels homes. I a les seues idees» (51).

La configuració de la realitat implica la presencia ostensible d'una estructura que precedeix l'acció del subjecte. Aquest marc confina el subjecte dins de certs valors culturals que seran després qüestionats i replantejats als poemes. Aquest punt configura l'ara i aquí de l'acció de les escriptores. La contextualització de l'aqui i l'ara influència i afecta les particularitats de l'acció. L'existència codificada en Sánchez-Cutillas dins el règim franquista i en Marçal en el moment de trencament d'aquest sistema, mesuren la seua individualitat femenina, la condicionen i determinen el punt de partida en referència a la categoria de dona específica a la que les dues pertanyen. Marçal es va referir específicament:

\footnotetext{
Entre els "valores eternos" que ens havia de transmetre, brillava la feminitat del drap de la pols i dels drapets de punt d'escapulari (....) si el cos semblava no tenir dret a l'existència, una via s'entreobria per a la ment (Barcelona BC, FMMM, "El punt de les dones", 16/6 full 1).
}

Aquests «valores eternos», de marcat caire religiós, inculcats i sostinguts institucionalment pel règim. es veuen plasmats poèticament també en totes dues escriptores encapçalats per una feminitat domèstica. Aquests valors pressuposen el xoc dialèctic en primer lloc d'una realitat que invoca 
les accions diàries $i$, per altra banda, l'absència d'aquesta quotidianitat del terreny de la cultura i com a possible tema poètic. ${ }^{4}$ És precisament el caràcter particular i específic d'aquestes activitats femenines inserides a l'interior de la casa, envers la pretesa universalitat dels temes poètics que preocupen l'home, el que fa que l'expressió d'aquest fragment de la realitat que viuen les dones no haja transcendit cap als horitzons de la poesia. Així, utilitzant la imatge de la pols i com a metonímia de l'activitat domèstica de la neteja de la casa, Carmelina escriu sobre aquesta quotidianitat com un càstig imposat, heretat, però també com a possibilitat de revolta. Ho fa al poema «La nostra rebel lió» del llibre Conjugació en primera persona:

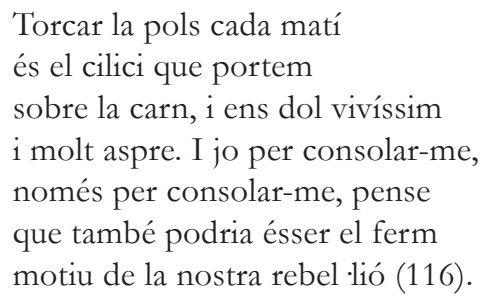

El caire religiós de la imatge, ple de dolor físic, patiment sobre la carn es manifesta de forma més pagana en Maria-Mercè al seu primer llibre i fa referència a aquesta realitat de la dona amb el poema inclòs al llibre Cau de llunes (1989: 47):

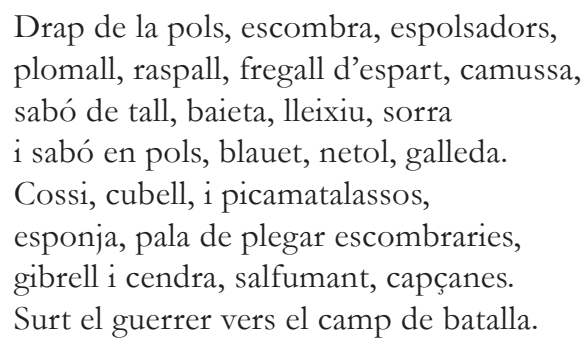

La intenció de Marçal de portar el tema de la quotidianitat de la dona com a material poètic era del tot conscient i derivada de la necessitat de reescriure els paràmetres culturals heretats i així trobar nous vincles de referència. Ella mateixa ho explica a una entrevista radiofònica l'any 1980 on diu que el poema és una referència irònica al catàleg de les naus dels guerrers de La Iliada d'Homer. La intenció de Marçal era fer un catàleg de les armes que utilitzen les dones cada dia i que mai han estat tema poètic. ${ }^{5}$ Allò que «els han dit que són», no cap, no és ja prou quan arriba el

4 La quotidianitat com a fita literària ha estat explorada en comparació als treballs de V.A. Estellés per Irene Mira (2017) a l'article «Un feix de coses petites: els espais de la quotidianitat en Carmelina Sánchez-Cutillas i Vicent Andrés Estellés».

5 El catàleg de les naus es troba al Cant II de La Il.liada d'Homer. Un dels passatges que comprenen els versos 480-760. Entrevista radiofònica al programa 'Solcant l'aire' de Ràdio Sant Boi el 22 de novembre 1980 va ser entrevistada per Maite Moreno i Joan Vilalta (http://www.fmmm.cat/arxiu) 
moment de l'escriptura i totes dues com a poetes impulsades pel desig de trencar, esgarren tota la codificació iconogràfica que les ha negades: «primer hi era un impuls estrany/ contrari a les idees/ que prevalien, malgrat/ el temps i els homes iracunds» (62). La proposta poètica a hores d'ara és ben clara i Marçal així ens ho diu:

\begin{abstract}
Cal restituir l'altra cara de la història, la veu de les dones. I aquesta la tenim tan emmascarada per allò que "ens han dit que som!" Prendre consciència d'això ha estat molt important $\mathrm{i}$ té moltes repercussions a nivell literari (Alzueta 1978: 7).
\end{abstract}

La realitat, el realisme imperant als poemes de Marçal i Sánchez-Cutillas, Cixous l'ha determinat com a fosc. Derivada de la premissa de Freud que va definir la identitat de la dona com un continent fosc, Cixous ens diu que aquest és el punt que ha fet que les dones interioritzen el fet de que viuen en la nit, dins l'obscuritat i que la foscor fa por i ha estat precisament aquesta por la que ha paralitzat la dona i l'ha exclòs de la cultura: «dark is dangerous. You can't see anyting in the dark, you are afraid. Don't move, you might fall. Most of all, don't go into the forest. And so we have internalized this horror of the dark» (1976: 878). Però Carmelina es mou, escriu des d'aquesta nit malgrat la por, com un impuls impossible de contenir i que en la seua força primigènia vol vèncer la mort:

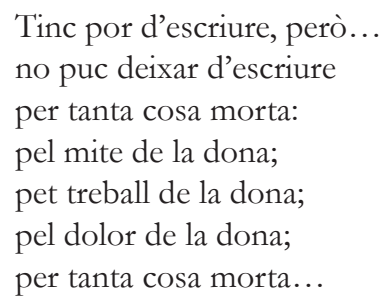

Carmelina al llarg dels dos primers llibres ens ho diu repetidament. Les imatges de la nit, la foscor i la por són recurrents: «tot és una llarga nit sense respostes. Tota la vida un desert fet de paraules/ no dites, de silenci amenaçant» (54) ens diu l'autora. Al poema «Jo era com una nit» ens ho explica: «Jo era com una nit /sense somnis./ Una nit sempre batuda» (102). Aquesta és però una foscor i una nit que parlen que senten i que escriuen. Així sent Carmelina el soroll, el remor que li batega dins la pell «time and time again I, too have felt so full of lumninous torrents that I could burst» (Cixous 1976: 876). Carmelina ho sent així constantment, aquests raigs de llum i repetidament la tremolor, el pols, el formigueig carregat de cert erotisme des d'on parla el cos i escriu fins que al poema «Conjugació en primera persona» li esclata per tot el cos, la paraula convertida en eixe torrent i que vol ser dita:

\footnotetext{
Tinc a la gola, al pols, un formigueig de versos, i a les cames també; aquestes cames que pels versos em tremolen tan lleument com si em llevàs de jeure amb un home, ara mateix (109).
} 
Noèlia Díaz Vicedo. Riuen les meduses: cos i desig a la poesia de Carmelina Sánchez-Cutillas i Maria-Mercè Marçal

«What is the meaning of these waves, these floods, these outburts?» es pregunta Cixous, el moviment del cos cap a la paraula i de la paraula al cos és sense dubte un acte de retorn, del desig de retornar d'una nit on la dona ha estat una vagabunda ${ }^{6}$ on ha caminat en cercles sense poder ixir a la llum «they have wandered around in circles, confined to the narrow room in which they have been given a deadly brainwashing» (1976: 877). El deure de Marçal i Sánchez-Cutillas com a poetes jau en rescatar de l'obscuritat i el silenci totes les experiències femenines. I aquesta és una de les funcions que té la literatura: «La literatura d'una banda "penetra" el sentit intern de la realitat. D'altra banda crea substituts de la realitat, interessos tangencials respecte als masculins» (BC, FMMM, 5/7, llibreta, fol. 107).

La realitat que ha estat «donada» $\mathrm{o}$ «habitada» per Carmelina i Maria-Mercè ha estat limitada al suport de la realitat de l'altre. En Carmelina, el jo poètic es veu vençut inserit dins el seu propi model que l'abastit: «em venç l'home...la casa..., l'home (...) els fills també em vencen, com si una nit de sobte, se m'haguessen fet gegants dins les entranyes...» però és la paraula, l'escriptura que la manté com diu a la conclusió del poema «i si escampe avui tantes paraules, per l'escombrim polsós / del meu silenci, és perquè tot açó m’espatlla» (112). Ara el món del jo poètic a Conjugació en primera persona es troba inserit en una quotidianitat feridora. Una ferida oberta des del fons del temps, d'un cos que dona vida però que l'han mort, neutralitzat, assimilat, xuclat endins la matriu de la casa i la història, i on el «nosaltres», «aquests vençuts» són les dones. Al poema «Venim del més lluny» és palés: «els homes ens han rebutjat des del cimall del conformisme, xuclant tot l'afront que els hem fet amb la nostra puresa» (57). Però Carmelina no es queda enrere, ni s'atura, ella en nom de les dones, de la Dona, investiga, escriu, venç al temps i recupera el cos i la veu: «Venim del mes lluny/ d'allà on es creuen tots els camins/ i el clam es fa inici i pren vida en nosaltres, que portem/ els crits tel lúrics/ la força avial dels incompresos,/ la veu antiga de la terra,/ i un nou missatge» (57). La conclusió del poema és definitiva amb la cronologia cultural i literària de la subjectivitat de la poeta: «I només ens cal, doncs,/ tornar arrere sense trofeus». Precisament és aquest procés de retorn el punt que ens comet en la tercera i última part d'aquest article.

\section{Mitologia i mites}

Carmelina Sánchez-Cutillas i Maria-Mercè Marçal no solament exploren sincrònicament el jo poètic des de les experiències vitals que conformen les seues realitats quotidianes sinó que totes dues fan una recerca diacrònica dels paràmetres que han determinat la relació de la dona amb l'escriptura i la literatura, conseqüentment amb la cultura. Aquest és un punt clau i determinant en les seues obres i que totes dues comparteixen. Carmelina amb el seu treball d'historiadora va fer una feina excel lent i meritòria respecte aquesta qüestió d'investigació de les arrels de la llengua i la cultura (Lacueva

6 El crític Enric Balaguer ens ha parlat de l'associació entre poeta i vagabund com les figures marginades i fora del sistema. Vegeu Balaguer (2020).

SCRIPTA, Revista internacional de literatura i cultura medieval i moderna, núm. 17 / juny 2021 / pp. 520 - 537 ISSN: 2340-4841 · doi:10.7203/SCRIPTA.17.20922 
Noèlia Díaz Vicedo. Riuen les meduses: cos i desig a la poesia de Carmelina Sánchez-Cutillas i Maria-Mercè Marçal

2019 i 2020), però és a través de la poesia que el seu jo poètic s’insereix directament dins de la diacronia de la línia històrica. El propòsit d'aquesta tasca és cercar el sentit, recórrer el camí invers per a poder situar-se al seu present històric. Així ho diu la poeta valenciana: «busque les arrels, la veritat, el sentit d'un món i d'una forma de vida més adient a les meues idees» (Ventura Melià 1979: 39). Marçal va trobar una connexió entre la fragmentació lingüística de l'escriptura de dones i la interpretació dels mites com els orígens de la cultura occidental. Tant Marçal com SánchezCutillas miren la mitologia com una forma de retorn a les arrels de la civilització occidental on la identitat de Dona es va configurar seguint allò que la filòsofa Luce Irigaray (1993: 11) va dir, que la cultura occidental es basa en un matricidi original. La utilització dels mites i la mitologia revela un enteniment més profund de les estructures que han operat en la construcció de la identitat de dona des d'un punt de vista històric mediterrani i patriarcal. Sue Blundell al seu llibre Women in Ancient Greece diu que fer un treball de revisió mitjançant la mitologia és important per a investigar estos mecanismes:

\begin{abstract}
These stories can help to reveal to us the response to women experienced by men living in a patriarchal society: what makes myth a very different source from, say, a philosophical treatise on the duties of a wife, is the fantasy element. Through myth we can reach the unconscious, rather than the logically-argued, notions which men entertained about women. In this way we can gain an insight into the symbolic value accorded to women -into what, in fact, the term 'Woman' meant to men (1995: 16).
\end{abstract}

Així mateix hi ha una connexió intrínseca i directa entre mitologia i poesia. La transmissió dels mites van ser majoritàriament a través de la poesia, i no podem oblidar que la poesia va ser la primera forma d'expressió escrita de la civilització occidental. Això ho podem veure a texts com La Teogonia d'Hesíode o a Homer amb La Ilíada. Aquests texts ens són testimoni del paper que han ocupat les dones i les imatges i significats que s'han transmès al llarg dels segles. La utilització de la mitologia com a mètode d'exploració en l'escriptura de dones contemporània en general ha estat estudiat per la crítica feminista des de quasi els seus començaments com a disciplina als anys setanta. El llibre pioner a establir un vincle entre crítica feminista i poesia Feminism and Poetry de Jan Montefiori publicat l'any 1987 va obrir un front important d'estudi on destaca la importància de la utilització de la mitologia com estratègia de creació i estudi al subjecte femení, sobretot pel que fa a la connexió entre mite i parla que estableix que el mite es pot definir al cap i a la fi com «a form of storytelling» (40). Encara que l'autora menciona el ressorgiment dels mites com a mètode d'estudi particularment de la mà de Sigmund Freud, ${ }^{7}$ Montefiore no ens diu que precisament el que distingeix la mitologia d'altres formes de contar és la dimensió iconogràfica i que precisament és aquest el nexe que connecta mitologia i poesia. No només perquè els mites donen forma a imatges

\footnotetext{
7 Sigmund Freud entre altres exploracions sobre mitologia va determinar el caràcter delimitant, opressor $i$ fins $i$ tot castrador de la mitologia cap a la identitat de la dona, entre d'altres, així el cap de Medusa, de la Gorgona representen els genitals femenins castrats. Vegeu 'Medusa's Head', The Standard Edition of the Complete Psychological Works of Sigmund Freud, Volume XVIII (1920-1922): Beyond the Pleasure Principle, Group Psychology and Other Works, p. 273-74.
} 
Noèlia Díaz Vicedo. Riuen les meduses: cos i desig a la poesia de Carmelina Sánchez-Cutillas i Maria-Mercè Marçal

específiques, com la poesia fa, sinó perquè la primera font d'informació que tenim escrita com hem dit sobre els mites ens ve donada de la mà de la poesia. ${ }^{8}$ I aquesta forma de contar va més enllà de la parla i la utilització de les imatges i de les possibilitats que connecten els fets naturals amb un significant simbòlic més profund. Allò que constitueix un mite i les contingències interpretatives és un tema que ha interessat molt també als estudis antropològics, psicoanalítics i històrics en general, $\mathrm{i}$ recordem que Carmelina n'era experta. En aquest nivell i dins de la tradició poètica catalana trobem també, sobretot pel que fa a la mitologia grega, els treballs d'Ausiàs March, Joan Roís de Corella, Jacint Verdager, Salvador Espriu com ja havia apuntat Alpera anteriorment, i el treball dels noucentistes quals Enric Balaguer es pregunta la referència com a possible influència en Carmelina al seu article «Poetes i vagabunds. Sobre la primera poesia de Carmelina Sánchez-Cutillas» (2020). I potser el crític no anava gens errat ja que Carmelina coneixia el treball d'Espriu com ens diu al següent passatge:

\begin{abstract}
Les meues preferències poètiques es redueixen a l'únic que conec, que és la poesia medieval, tant la nostra com la castellana, la francesa i la de Portugal. I l'obra dels trobadors, llunyans i estimats... ara bé, conec i admire l'obra de Salvat-Papasseit i d'Espriu, dos poetes molt diferents, però que m'agraden molt (Del Romero 2020: 40).
\end{abstract}

Carmelina, com hem dit abans, situa el seu jo poètic directament dins la línia mitològica al seu poemari Els jeroglifics i la pedra de Rosetta publicat l'any 1976 i del que s'ha dit que és el poemari més complex i interessant de la poeta. Lluís Alpera a l'estudi introductori que fa a la poesia completa el compara com hem dit amb La pell de brau i Semana Santa d'Espriu i ens diu que «és un dels més originals $i$ interessants de tota la recerca formal i estètica produïda en el camp de la poesia al País Valencià als anys setanta» (17). M. Àngels Francés a l'article «Una travessa pel laberint: Assaig d'interpretació de Els jeroglífics i la pedra de Rosetta, de Carmelina Sánchez-Cutillas» (2015) fa un estudi minuciós i tremendament interessant i il luminador analitzant-lo des de la perspectiva dialògica bakhtiniana i el concepte d'intertextualitat de Julia Kristeva. ${ }^{9}$ Així i tot, la pròpia Carmelina contradiu les expectatives esmentades per la crítica contemporània i mostra la incomprensió i fins i tot la decepció que sent pel fet que la crítica en el seu moment va restar completament muda a la publicació del poemari:

del llibre El jeroglific $i$ la pedra de Rosetta no vull parlar. Si he fet alguna cosa bona i intel ligent, és aquest llibre. Ara bé, possiblement és un llibre per a minories. Clar que també pense que el pitecantropus erectus, o dit més suaument l'homo sapiens llig allò que l'editor o els crítics volen (Alpera 1997: 19).

La diferència del llibre Els jeroglifics $i$ la pedra de Rosetta respecte als seus dos primeres col leccions és ben palesa no només per la temàtica que ja s'entreveu des del títol del poemari sinó també per

8 Per a més detalls de la relació entre mite i poesia a la literatura catalana vegeu Bartra (1980).

9 També en parlen Grau (2000) i Cassasses (2009).

SCRIPTA, Revista internacional de literatura i cultura medieval i moderna, núm. 17 / juny 2021 / pp. 520 - 537 ISSN: 2340-4841 · doi:10.7203/SCRIPTA.17.20922 
Noèlia Díaz Vicedo. Riuen les meduses: cos i desig a la poesia de Carmelina Sánchez-Cutillas i Maria-Mercè Marçal

l'estructura poètica. Els vint-i-huit poemes sense títol i numerats del llibre estan escrits en prosa poètica, una estructura adherida al nucli del mite com a narració d'històries. Encara més, mentre que les referències literàries, històriques i culturals són pràcticament inexistents en els dos primers llibres, a excepció d'uns quants exemples, aquest tercer complet és una composició iconogràfica i polifònica que Francés ha denominat, utilitzant la terminologia bakhtiniana, com «una caixa de ressonància» (2015: 12). La dimensió iconogràfica és de fet un espai poderós i revelador, on l'autora exigeix del lector un ampli coneixement, no només històric sinó cultural i mitològic, i d'una amplària que s'estén per tota la mediterrània d'est a oest i on Carmelina va excavant les complexitats i contradiccions de les estructures de poder que han rodejat el subjecte poètic: «aquest és un llibre estrany» ens diu la poeta «producte de totes les cultures que han passat per mi; és com si fos un cove ple de materials de gratada de tota mena» (Del Romero 2020: 42). La línia temporal de la cultura occidental detallada al llibre i l'espai simbòlic dels paràmetres que les representen, troben que les gestes que comparteixen el marc comú de la mitologia pertany a tres grans eixos principals: hel lènica, egípcia i la cristiana-medieval (que no es pot entendre sense la inclusió del mon àrab, l'islam i el judaisme). Així i trobar-se el jo poètic anacrònicament, l'escriptura segueix sent font de desig i el desig d'escriure segueix manifestant-se en el cos, entre la tremolor del poeta: «els llavis del poeta tremolen» diu al poema 5, el plor que recurrentment apareix al llarg del llibre: «ploraré amb la rosada si les canyes es dobleguen al pas del fugitiu» (poema 4). En aquest cos de vegades mutilat, alterat, es troben les «paraules...paraules...però el símbol i el dogma esclavitzen tot un poble de circumcisos» (Poema 9, 168). I també «la paraula que denuncia o que lloa. Sempre la paraula i la veu del poeta al balanceig de tots els vents» (poema 14, 173). I el poeta sensible i amb angoixa constant va demanant, va escrivint, va qüestionant mentre el jo poètic va obrint l'espai simbòlic, eixamplant la línia temporal i inscrivint els seus desitjos. Ja no és qüestió de provocació, de llençar pedres, la rebel lia de les paraules que ja havia començat al primer poemari ha donat pas a la destrucció total: «ara, la meua veu s'ha fet de pedra i no podré llançar el missatge rebel. Una flama intensa, fluorescent, em crema per la nit!» (poema 12, 171).

Marçal pel contrari no va utilitzar la mitologia a la seua poesia però si com a eina de pensament. Igualment Cixous, en referir-se exactament a les delimitacions que el patriarcat a través de la llengua ha imposat a la identitat de la dona utilitza una de les imatges més importants de la història del pensament i cultura occidental: la Medusa i així la dona, segons Cixous, ha estat delimitada entre Medusa i l'abisme: «they riveted us between two horrifying myths: between the Medusa and the abyss. That would be enough to set half the world laughing, except that it's still going on» (1976: 885). Medusa és la figura que, segons Sue Blundell (1995: 17), pertany a la tercera classificació d'éssers femenins que apareixen als mites (la primera correspon a les divinitats amb les sis deesses i la segona a les humanes). Aquest tercer grup el comprenen les monstres, és a dir, les criatures que són meitat dones i meitat animals. Medusa és una de les tres Gorgones, que tenien el poder de convertir els humans en pedra si s'atrevien a mirar-les. La seua aparença lletja $i$ terrible es connecta amb la seua morfologia, tenien el cabell de serps, les ales daurades i ullals. Medusa és una criatura anòmala amb forma híbrida i que identifica el cos de la dona amb les forces de la natura. Blundell 
Noèlia Díaz Vicedo. Riuen les meduses: cos i desig a la poesia de Carmelina Sánchez-Cutillas i Maria-Mercè Marçal

interpreta la presència d'aquestes criatures monstruoses i mítiques amb la representació d'una por específica: «fear which women inspired to men» (1995: 17), por a la qual s'ha referit també Cixous (1976: 885):

\begin{abstract}
men say that there are two unrepresentable things: death and the feminine sex. That's because they need femininity to be associated with death: it's the jitters that gives them a hard-on! For themselves! They need to be afraid of us.
\end{abstract}

Aquesta por que sembla trobar-se en la capacitat de les dones de «generar» es manifesta al mite a través de imatges femenines com horribles, sers sense cor. Medusa és perillosa, maligna i amb una mirada autodestructiva que porta la força fosca que té el poder de petrificar. Aquesta mena de força destructiva és precisament identificada amb l'acció de l'escriptura de la dona poeta: la capacitat de trencar l'ordre de la bellesa i l'harmonia del patriarcat en el qual la dona és absent.

La imatge de Medusa en relació a la dona escriptora també va ser de gran interès per a Maria-Mercè Marçal que la va portar a escriure l'assaig «Mes ençà i més enllà del mirall de la Medusa» (1996a) on precisament la poeta analitza la posició de la dona escriptora dins de la cultura. Marçal utilitza el mite del naixement d'Atenea per a explicar la situació. Diu:

\footnotetext{
Atenea neix del cap de Zeus, qui, prèviament, s'havia empassat Metis, divinitat associada a una certa saviesa ancestral femenina. Menjant-se-la, Zeus n'assimila en part el seu poder. (...) d'aquest estrany part invertit -normalment és home qui neix de dona i no al contrari- Atenea en surt completament vestida i armada: sense contacte inicial amb la seva pròpia nuesa (163)
}

Desfer els fils que ha cosit la tradició entre el jo poètic de les autores i l'espai cultural, entre la línia que connecta el passat i el present. És evident en l'obra de Sánchez-Cutillas i en Marçal la confrontació anacrònica de la identitat de dona respecte a les seues experiències vitals i personals. Medusa, pel contrari apareix a l'escut d'Atenea com un regal que Perseu li ofereix per haver-lo ajudat a decapitar-la. Marçal la descriu com a símbol del caos i la monstruositat: «dona monstre, el femení indomenyat, salvatge i perillós. Mirada petrificadora d'allò que és exclòs, no dit, que, encarada al mirall, s'ha petrificat a si mateixa» (1996a: 164). Monstre i paraules no dites encarades al mirall de la poesia, en Sánchez-Cutillas també:

\footnotetext{
la sensibilitat del poeta; l'atracció dels astres; la teoria de la relativitat; la paraula verge que encara no hem dit; el plany de la bèstia ferida; el riu egipci negant les tombes dels Faraons...entre el misteri i nosaltres sempre hi ha una pluja roent de profecies incomprensibles (Poema 7, 165).
}

Com podem veure el cos de la dona en les tres imatges roman assimilat amb Metis, cobert amb Atenea o decapitat amb Medusa. Cap de les tres dones ha estat en contacte amb el seu propi cos, el desconeixement, la desconnexió i la fragmentació es completa. Així Marçal estableix que l'acció 
Noèlia Díaz Vicedo. Riuen les meduses: cos i desig a la poesia de Carmelina Sánchez-Cutillas i

Maria-Mercè Marçal

de la dona que escriu oscil la entre les dues Atenea i Medusa: «movent-se entre la Llei del pare que organitza el món tot excloent-la i/o inferioritzant-la en tant que dona, i el femení inarticulat, caòtic» (1996a: 164). L'exclusió d'inferioritat és paral lela al desconeixement i el silenci que descriu Sánchez-Cutillas, que utilitza el mite de la filla d'Agamèmnon i Clitemnestra per referir-se a aquesta situació de subordinació i poder per part del patriarcat des de la mitologia:

des de sempre la dona ha estat subordinada a la voluntat, al caprici, als desitjos i, fins i tot a la crueltat de l'home. Ara em ve a la memòria Ifigènia, la filla d'Agàmenon i Clitemnestra, sacrificada als déus per tal que la flota grega assolirà vents favorables. Quantes Ifigènies, desconegudes i silenciades, han passat, passen per la història? (Del Romero 2020: 50).

\section{Conclusió}

La conclusió derivada de les propostes de revisió diacròniques i sincròniques a través de la mitologia, la realitat i la interacció entre vida i literatura de l'obra poètica de Maria-Mercè Marçal i Carmelina Sánchez-Cutillas remet a una escletxa, un buit identificat en la fragmentació interna que les autores experimenten entre cos i llenguatge, entre el seu cos de dona i la subjectivitat com a poetes. Una fragmentació que es converteix en allò que Carmelina ha definit com desarrelament i així li ho confessa al seu amic Guillem de Berguedà fet d'ivori «sembla que estem els dos, únics espectadors, assistint al funeral de tots els poetes, de tots els rebels, de tots els desarrelats del món; d'un poeta, d'un rebel, d'un desarrelat» (Del Romero 2020: 72). Maria-Mercè ho identifica com un sentiment d'estranyesa que li causava fúria «un sentiment massa intens, violent, de fúria, que em feia un nus a la gola i no em deixava parlar, el que s'interposava entre jo i el text» (1993: 137). Així hem vist, en aquest article, que aquesta desconnexió entre dona i escriptura ve donada pel cos a qui l'escriptura repta: al fat inexorable, en paraules de Marçal, el fat que concep la dona exclusivament com a mare. Aquí comença la pugna de les dues posicions enfrontades, «jo passe les hores entre paelles i perolets, i els dies se'm moren sense adonar-me'n i el deler d'escriure se'm fon per entre els venes i m'espatlla. Jo, amanint els menjars, i ensems passant fam de quartilles» (33). Fam que fa sang, però que no es qualla, que brolla, viva i punyent en cada vers, en cada paraula en cada instant que les poetes agafen la ploma i escriuen. En cada moment que participen activament en el procés de creació contribuint així a la baula de la tradició i la història. He analitzat com l'escriptura en Marçal i Sánchez-Cutillas és sempre un acte de retorn i que aquest acte és inseparable del cos i que el cos, a través del llenguatge és capaç de generar nous significats, tot i ferit i potent, i que no remet a la concepció essencialista i exclusiva de la carn, sinó que oscil la entre Atenea i Medusa, la natura i la cultura, present i passat des de la diferència sexual, confirmant la poesia com l'espai on les poetes escriuen el desig $i$ on el desig d'escriure manifesta "precisely the very possibility of change, the space that can serve as a springboard for subversive thought, the precursory movement of a transformation of social and cultural structures» (Cixous 1976: 879) i aquest és sense cap dubte la raó poètica compartida, la continuïtat genealògica i que totes dues escriuen més enllà de la pell. 
Noèlia Díaz Vicedo. Riuen les meduses: cos i desig a la poesia de Carmelina Sánchez-Cutillas i Maria-Mercè Marçal

\section{Bibliografia}

Alpera, Ll. (1997) «Introducció», dins Carmelina Sánchez-Cutillas, Obra poètica, València, Generalitat Valenciana, p. 9-36.

Alzueta, M. (1978) «Maria-Mercè Marçal de classe baixa i nació oprimida», Mundo Diario, 6 juliol, p. 6-7.

Balaguer, E. (2020) «Poetes i vagabunds. Sobre la primera poesia de Carmelina Sánchez-Cutillas», Saó, 461, p. 4-6.

Bartra, A. (1980) Sobre poesia, Barcelona, Laia.

Blundell, S. (1995) Women in Ancient Greece, London, British Museum Press.

Borja, J. (2001) «Carmelina Sánchez-Cutillas. Matèria de memòria» dins Literatura autobiogräfica: bistòria, memòria i construcció del subjecte, Paiporta, Denes.

Boscà, V. (2020) «Entrevista a M.Àngels Francés i Joan Borja», Saó, 461, p. 12-15.

Cacciola, A. (2019) «Carmelina Sánchez-Cutillas: Deconstrucción y reconstrucción identitaria femenina desde la marginación», Lectora, 25, p. 287-306.

Cassasses, E. (2009) «Porpra i caretes per als germans», El País, 26 febrer, p. 8.

Cixous, H. (1976) «The Laugh of Medusa», traduït per Keith Cohen / Paula Cohen, Signs, Vol. 1, 4, p. 875-893.

Del Romero Sánchez-Cutillas, L. (2020a) La meva cambra més estimada. La biblioteca de Carmelina Sánchez-Cutillas, València, Vincle.

—. (2020b) «La biblioteca de Carmelina Sánchez-Cutillas», Saó, 461, p. 20-22.

Díaz Vicedo, N. (2014) Constructing Feminine Poetics in the Works of a Late-20th-Century Catalan Woman Poet: Maria-Mercè Marçal, Cambridge, MHRA.

- (ed.) (2017) Maria-Mercè Marçal. Her Life in Words, London, ACSOP.

Díaz Vicedo, N. / Abelló M. (2014) The Body's Reason, traducció de Raó del cos de Maria-Mercè Marçal, London, Francis Boutle Publishers.

Esteve, A. (2017) «Un passat on retrobar-se. Memòria i identitat en l'obra poètica de Carmelina Sánchez-Cutillas», L'Aiguadols, 46, p. 29-40.

—. (2020) «Memòria i identitat en l'obra de Carmelina Sánchez-Cutillas», Saó, 461, p. 7-11.

Francés, M. À. (2015) «Una travessa pel laberint: assaig d’interpretació de Els jeroglifics i la pedra de Rosetta de Carmelina Sánchez-Cutillas», Caplletra, 58 (Primavera), p. 9-28.

Irigaray, L. (1993) Sexes and Genealogies, New York, Columbia University Press. 
Noèlia Díaz Vicedo. Riuen les meduses: cos i desig a la poesia de Carmelina Sánchez-Cutillas i Maria-Mercè Marçal

Lacueva Lorenz, M. (2019) Les dones fortes. La narrativa valenciana sota el franquisme, València, Institució Alfons el Magnànim.

- (2020) «Recuperar la història (també) en femení. L'aportació de Carmelina Sánchez-Cutillas», Saó, 461, p. 16-19.

Marçal, M-M. (1989) Llengua abolida (1973-1988), València, $3 i 4$.

-. (1994) La passió segons Renée Vivien, Barcelona, Columna.

— .(1996a) «Més enllà i més ençà del mirall de la Medusa» dins Ibarz M. (ed.) (2004) Maria-Mercè Marçal. Sota el signe del drac: Proses 1985-1997, Barcelona, Proa, p. 155-66.

- (1996b) «Elogi del drac» dins Ibarz M. (ed.) (2004) Maria-Mercè Marçal. Sota el signe del drac: Proses 1985-1997, Barcelona, Proa, p. 35-39.

Mira Navarro, I. (2017) «Un feix de coses petites: els espais de quotidianitat en Carmelina SánchezCutillas i Vicent Andrés Estellés», L'Aiguadolc, 46, p. 41-54.

Montefiore, J. (1987) Feminism and Poetry, London and New York, Pandora.

Montero, A. (2004) «Anna Montero entrevista Maria-Mercè Marçal», Lectora, 10, p. 259-84.

Nadal, M. (1989) «Converses literàries: Maria-Mercè Marçal, els confins de la identitat», Serra d'Or, 352 , p. 24-28.

Riba, C. (2014) Maria-Mercè Marçal. L'escriptura permeable, Vic, Eumo.

- (2015) Cos endins. Maternitat, desig i malaltia en l'obra de Maria-Mercè Marçal, Girona, Curbet.

Sánchez-Cutillas, C. (2020) Matèria de Bretanya, València, $3 i 4$.

Tanna, N. (2019) Queer Genealogies in Transnational Barcelona: Maria-Mercè Marçal, Cristina Peri Rossi, and Flavia Company, Studies in Hispanic and Lusophone Cultures, 37, Cambridge, Legenda.

Ventura Melià, R. (1979) «Carmelina Sánchez-Cutillas. Sóc independent, rebel i bohèmia», Valencia Semanal, 82 (29 juliol-5 agost), p. 38-39. 